\title{
Die verband tussen die ontwerp en prestasie van seilplanke
}

\author{
K.F. Kriel* \\ Departement Menslike Bewegingskunde, Potchefstroomse Universiteit vir Christelike Hoër Onderwys, Potchefstroom 2520
}

H.S. Steyn (jr.)

Statistiese Konsultasiediens, Potchefstroomse Universiteit vir Christelike Hoër Onderwys, Potchefstroom 2520

Ontvang 20 Augustus 1991; aanvaar 20 Junie 1992

\section{UITTREKSEL}

Ontwerpe en prestasies van 175 van die nuutste seilplanke, soos in die literatuur vermeld en op die mark, is statisties ontleed om vas te stel of die bewerings wat ontwerpers en vervaardigers oor die prestasie van hulle ontwerpe maak, werklik waar is. Terselfdertyd word die omva. gryke meningsverskille van ontwerpers en vervaardigers ook onder die loep geneem. Die verskillende vorms is in verband gebring met prestasie ten opsigte van erg windop, windop, $90^{\circ}$ met die wind, $120^{\circ}$ windaf, windafdraaivermo $\ddot{~}$ en prestasie in ligte-, medium- en sterkwindsnelhede. Statistiese analises deur middel van verskillende stadiums van meervoudige regressie het aan die lig gebring dat die verskillende vorms van seilplanke kollektief tot $59 \%$ bygedra het in die verklaring van die variansie van sekere aspekte van prestasie.

\section{ABSTRACT}

Relationships between the design and performances of sailboards

The shapes and performances of the 175 most recently designed sailboards recorded by testers in different sailboard magazines are statistically correlated to establish whether shapes are in fact responsible for performances as claimed by designers and manufacturers. Different shapes are correlated with different aspects of performance, namely up-wind, reach, broad reach, lightwind performance, medium-wind performance, strong-wind performance and jibes. Statistical analysis by means of different stages of multiple regression showed that different shapes of board collectively contributed in some cases to explaining up to 59\% of the variance between certain types of performance.

*Outeur aan wie korrespondensie gerig kan word. 


\section{LITERATUURSTUDIE, PROBLEEM EN DOEL VAN DIE ONDERSOEK}

'n Literatuurstudie het aangetoon dat menige vormaspekte van seilplanke 'n invloed op die prestasies van sulke planke het. ${ }^{122.2437 .3954}$ Meningsverskille bestaan ${ }^{24-35,42,48}$ of sekere vorms werklik bydra tot die onderskeie prestasies van seilplanke. Die verskillende vorms van seilplanke soos konkaaf, stertboog, ens. se invloed op die prestasies van sulke seilplanke onder verskeie see- of watertoestande soos versnelling, ligtewindryvermoë, ens., uit die literatuur, is in tabel I saamgevat. Dit is ook duidelik dat geen algemene neigings uit tabel 1 bepaal kan word nie en dit het gelei tot die spesifieke analise wat gedoen is. Die doel van hierdie studie is om soveel moontlik seilplankvorms statisties met aspekte van hulle prestasie te korrelleer, om vas te stel of daar vorms is wat 'n bydrae lewer tot die prestasie van seilplanke. Die belangrikste terminologie wat in hierdie artikel gebruik word, word verklaar.

\section{TERMINOLOGIE}

Die terminologie wat in die artikel gebruik word, word aan die hand van figuur I -4 soos volg verklaar:

Figuur 1 Afrikaans

agterstewe

boeg

drukarea

kiel

neusboog

skeringsarea

stuwingsarea

vin

voetbank

Figuur 2

$\begin{array}{ll}\begin{array}{l}\text { Dill-vorm } \\ \text { dik sy }\end{array} & \text { Dill shape } \\ \text { boxy rail } \\ \text { koëlvorm } & \text { gun shape } \\ \text { slanke sy } & \text { non boxy rail } \\ \text { spoedvorm } & \text { speed shape } \\ \text { vrystylvorm } & \text { free style shape }\end{array}$

Figuur 3

Afrikaans
diamantstert
gekromde sy
geronde speldstert
geronde sye
gladde sye
panele
plat bodem
plat stuwingsy
plat sy
prominent
(diep vorms)

(diep vorms)

sharp

skerp sye sharp rails

speldstert pintail

stompstert squad tail

subtiel (baie vlak,

sagte vorms) subtle

swaelstert swallow tail

trap V-vorm step vee

vlerkstert winger

$V$-stuwingsy vee planing rails

V-vorm vee shape

Figuur 4

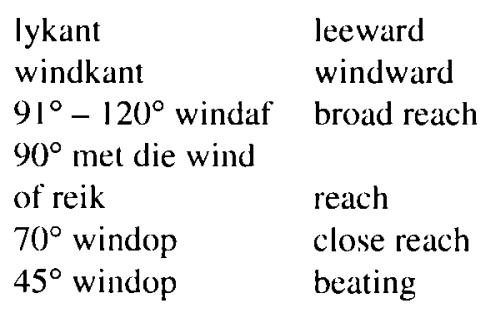

Terme wat nie in figuur $1-4$ verklaar word nie, is die volgende: branderseilplank ("wave board"), erg windop ("tack or point"), sterkwind-slalomseilplank $( \pm 2,7 \mathrm{~m}$ en kleiner), oorboeg of om windop te draai ("tacking"), opstu ("lift"), reuse slalomseilplank ("gaint slalom board"), skeer ("plane"), slalomseilplank ( $\pm 2,92 \mathrm{~m})$, sleur ("drag"), syvinne ("thrusters"), takelasie ("rig"), vinverlies ("spin out"), windaf draai ("jibe"), windop ry ("point") en spring (golfspringvermoë).

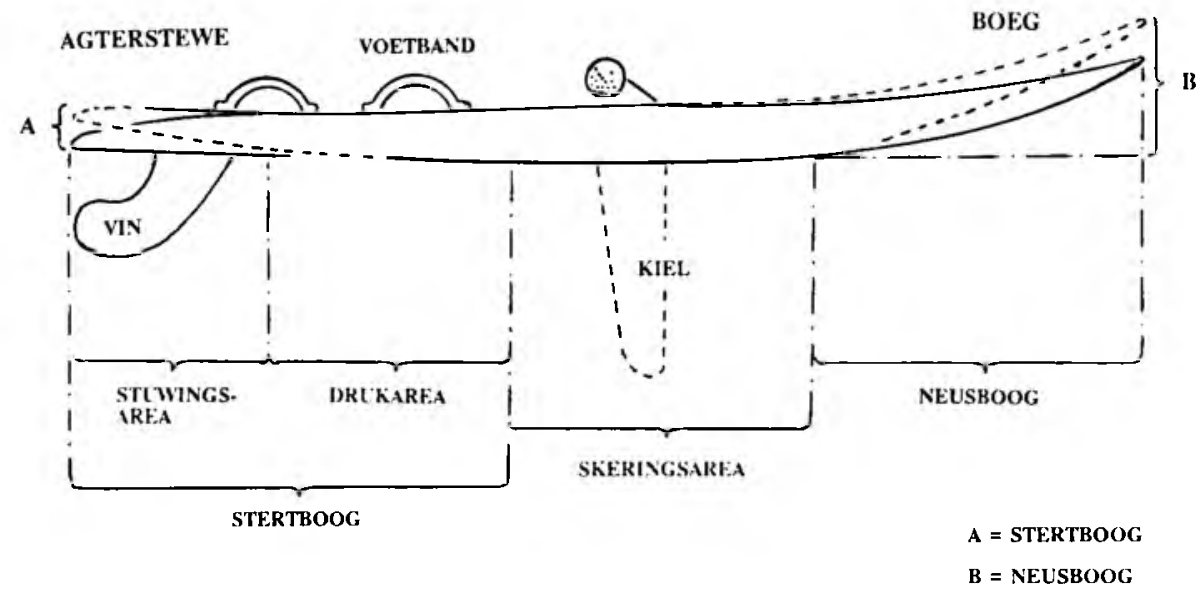

FIGUUR I: Die verklaring van terminologie volgens die sy-aansig. 
TABEL 1

Die invloed van ontwerpvorms op die prestasie van seilplanke onder sekere gebruikstoestande soos in die literatuur vermeld. Die norme, waar beskikbaar in die literatuur, word in die ooreenstemmende blokkies aangedui.

Die volgende norme geld: < = verminder; > = vermeerder; 0 = dra niks by tot; + = dra by tot; - = nadelig vir; $\$=$ beter ryvermoë in; $\&$ = tydens skeer; \# = geen beter ryvermoë

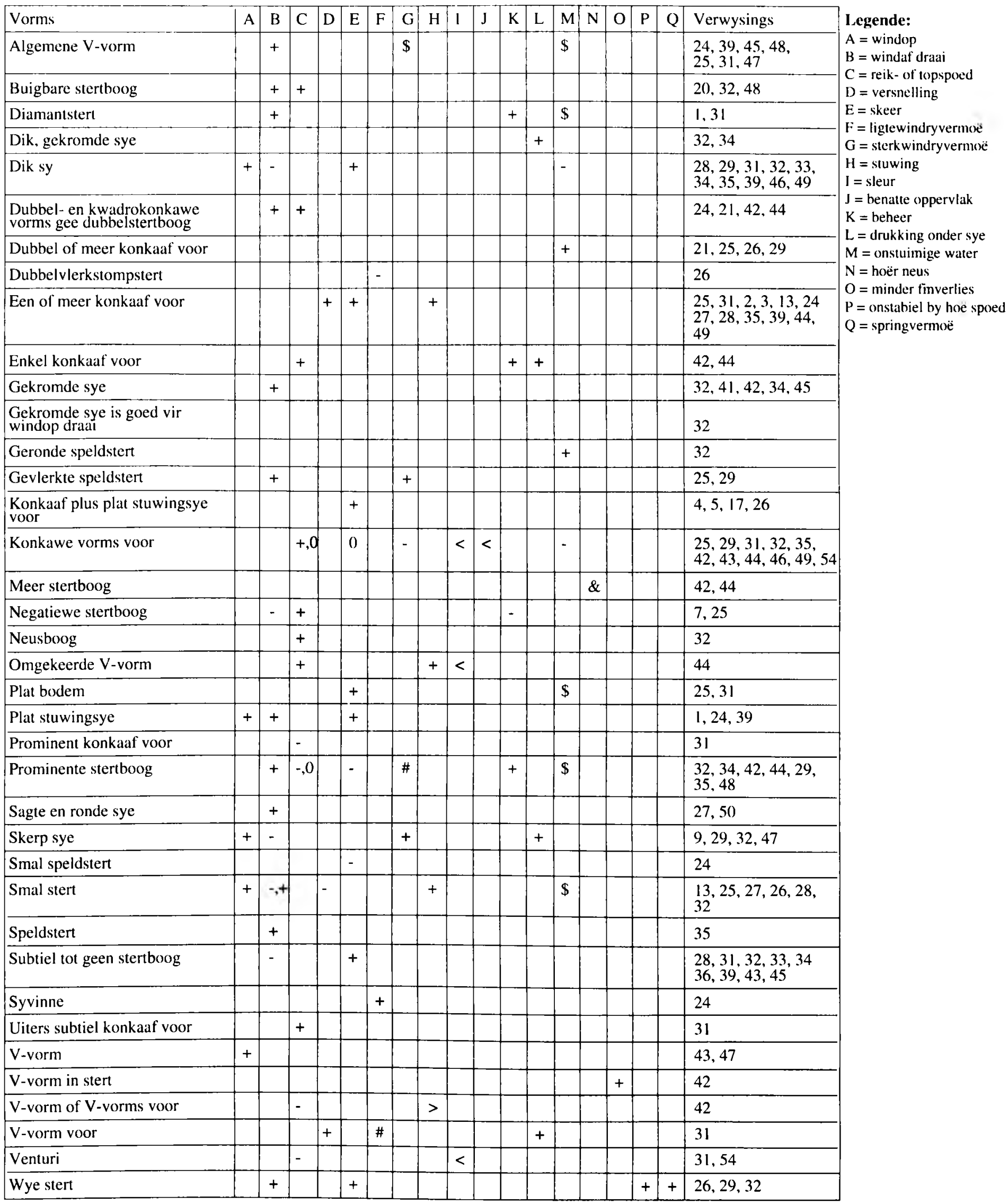




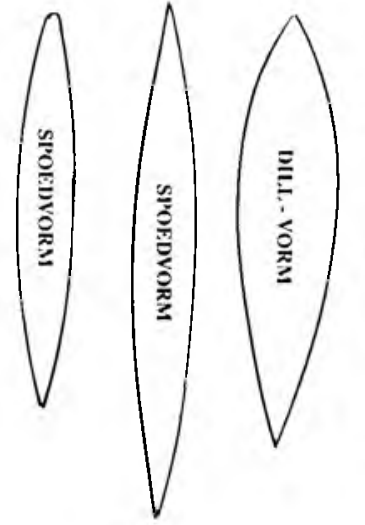

SKAAL: 1 CMT $=0,3 M$

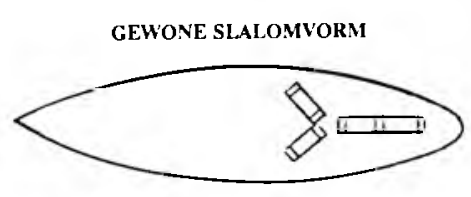

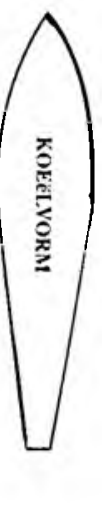

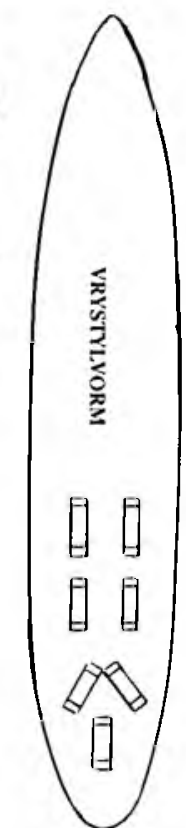

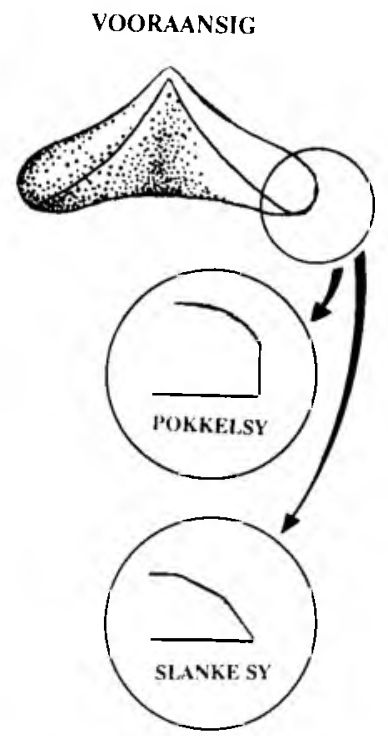

FIGUUR 2: Verklaring van terminologie volgens planvorms, vooramsig en sye.

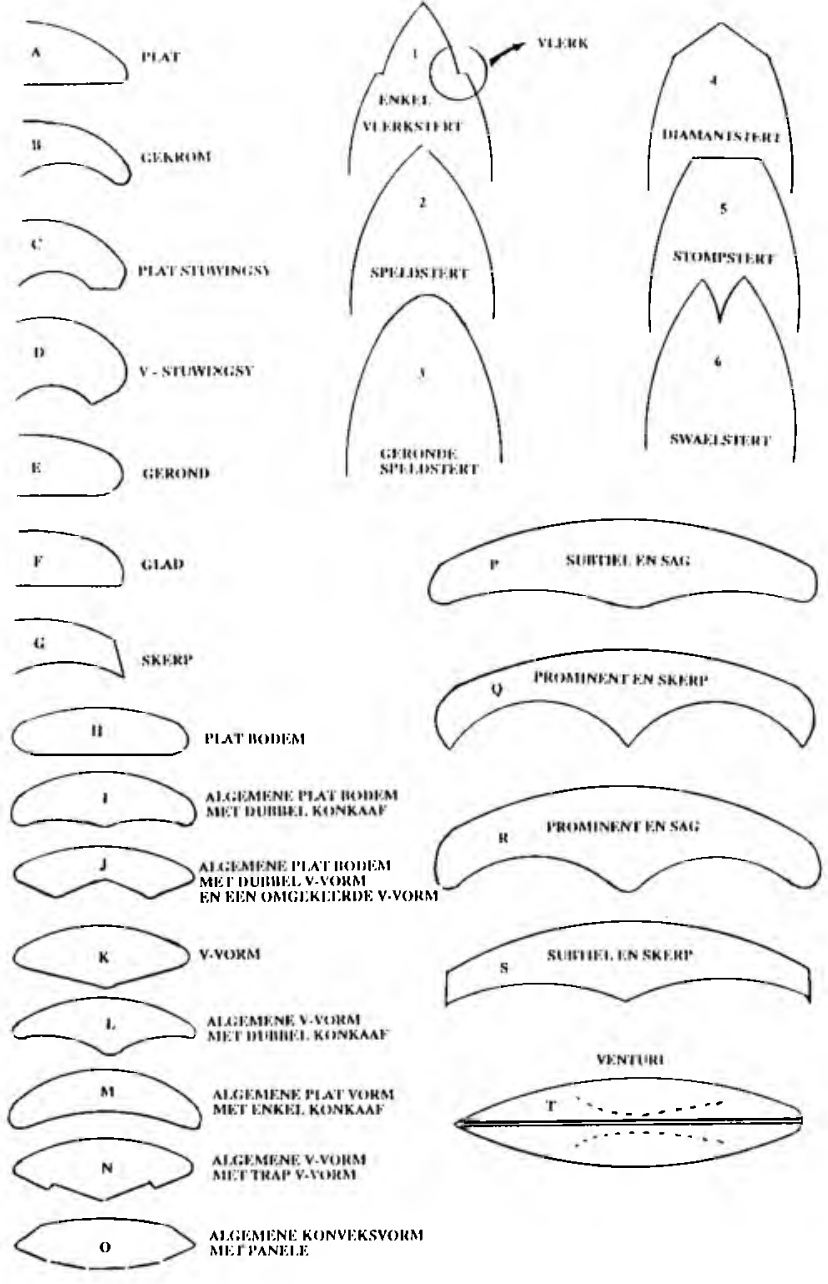

FIGUUR 3: Die verklaring van vorms; $A-S=$ Dwarsdeursne $\ddot{e}$; $=$ Planvorm $; 1-6=$ Stertvorms.

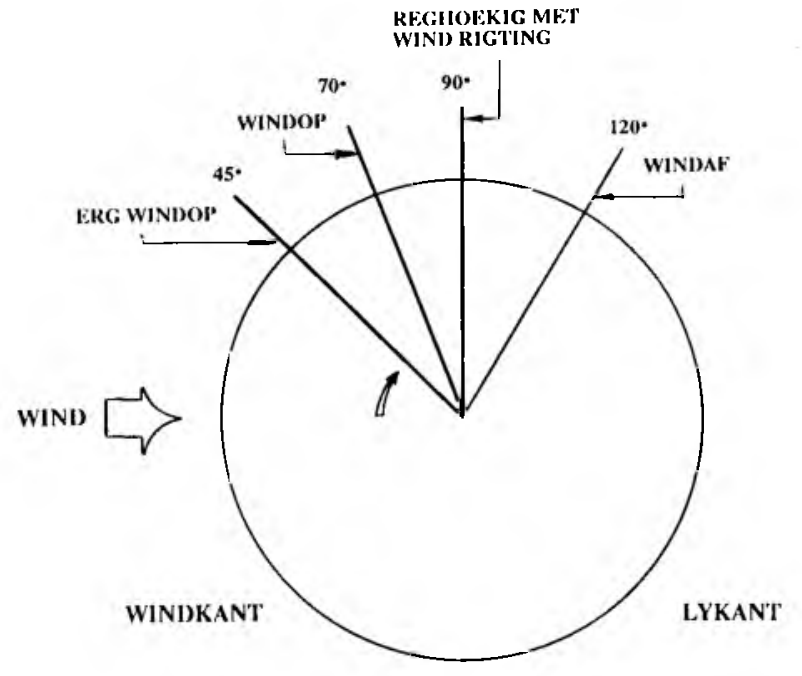

FIGUUR 4: Die seilrigtings waarvolgens planke getoets is.

\section{METODE}

Kwantifisering van seilplankvorms (onafhanklike veranderlikes)

Die tegniese toetse van styfheid, volume, varswaterdryfbaarheid, soutwaterdryfbaarheid, en massa word in Le Mehaute $^{40,41}$ beskryf. In tydskrifte $1-18,19-20,24-35,36,37,46-52$.

${ }^{53}$ meet en rapporteer toetsafnemers lengte en breedte in meter, volume in liter en massa in kilogram. Die toetsafnemers beskryf die seilplankvorms dan subjektief soos volg: 'n algemene plat vorm, 'n prominente enkel tot dubbel konkaaf tot 'n subtiele V-vorm met skerp, dik sye, 'n wye stert, groot neusbuiging en min stertbuiging. Hierdie vorms is vir die statistiese analises as teenwoordig of afwesig (digotome data) gekodeer. In enkele gevalle is neusbuiging en stertbuiging deur toetsafnemers in meter gemeet. Alle veranderlikes is egter nie altyd deur toetsafnemers gerapporteer nie.

Algemene vorm

Op die algemene vorm van seilplanke kan ander vorms 
ingebou word (figure 2 en 3). Die vorms is gekodeer deur teenwoordigheid of afwesigheid (digotome data) vir die volgende vorms toe te ken: skerp, plat, V-vorm, konveks, konkaaf, omgekeerde V-vorm, en venturi. Die vorm "subtiel" vir die algemene seilplankvorm; die voorste driekwart en die agterste deel van die seilplank is uit die analises weggelaat. Die rede hiervoor word in die bespreking behandel.

\section{Voorste driekwart}

Die voorste driekwart van 'n seilplank se onderwatervorm verskil gewoonlik van die agterste kwart, want alhangende van seilplankspoed en seilrigting kan verskillende dele van 'n seilplank in die water wees. ${ }^{42,31}$ Die voorste driek wart van 'n seilplank se onderwatervorms is soos volg digotoom gekodeer: skerp, plat, V-vorm, konveks, konkaaf, omgekeerde V-vorm, venturi, trap V-vorm, plat stuwingsye, $\mathbf{V}$-stuwingsye en panele (figuur 3 ). Die getal vorms wat voorkom, byvoorbeeld kwadrokonkaaf, is as ordinale data gekodeer.

\section{Agterste kwart}

Die vorms van die agterste kwart is soos volg digotoom gekodeer: skerp, plat, V-vorm, konveks, konkaaf, omgekeerde V-vorm, panele, en 'n trap V-vorm (figuur 3 ). Die getal vorms wat voorkom, is as ordinale data gekodeer.

\section{Stertvorm}

Die stertvorms is ook ordinaal soos volg gekodeer: smal ( 1 ), medium (2) en wyd (3) as een veranderlike, geen vierk (1), een vlerk (2) en twee vlerke (3) as nog 'n veranderlike en die res as digotome veranderlikes (figuur 3 ). Die veranderlikes speldstert, ronde speldstert, diamantstert, stompstert en swaelstert is ook digotoom gekodeer.

\section{Rande}

Die volgende sye is digotoom gekodeer: dik sy, gekromde sy, ronde sy, gladde sy, skerp sy (figure 2 en 3 ). Die veranderlike "gladde sy" is weggelaat omdat dit reeds ten volle deur die ander veranderlikes beskryf word in die sin dat indien geeneen van eersgenoemde sye voorkom nie, dit laasgenoemde impliseer.

Ander ordinale data waaroor daar min deur die toetsafnemers gerapporteer word, is: neusboog in meter, stertboog in meter, neuswydte in meter, stertwydte in meter, varswaterdryfbaarheid in liter, soutwaterdryfbaarheid in liter en styfheid van die plank in kilogram.

Kwantifisering van prestasie (afhanklike veranderlikes) Die prestasiedata is die subjektiewe beoordelings van toetsafnemers. Dunstan-Smith ${ }^{1-18}$ beskryf geen toetsprosedures nie en hy klassifiseer die prestasie van die seilplanke op 'n skaal van $0-20$ wat vir hierdie studie na persentasies omgewerk is. Rogers ${ }^{46-52}$ \& Le Mehaute ${ }^{41}$ beskryf weinig toetsprosedures, behalwe dat dieselfde takelasie gebruik word, en gee die prestasie op 'n persentasieskaal weer. James ${ }^{21,34}$ soek die toetsers uit en gebruik byvoorbeeld persone wat vervaardigers van planke of seile is, baie toetsondervinding $(5-10$ jaar $)$ het, kampioene is, nie omkoopbaar of geborg is nie, in verskillende gewigsklasse val $(52,2 \mathrm{~kg}$ tot $90,9 \mathrm{~kg}$ of meer), spesialiste van verskillende windtoestande is en seilplankryers (van beide geslagte) is. Ses toetsers gee dan elkeen 'n evaluasie van goed, gemiddeld of sleg deur die duim op te steek vir goed, dit gelyk te hou vir gemiddeld en af te wys vir sleg. Dit is vir hierdie studie soos volg na $\%$ omgewerk: 1 duim op = $17 \%, 1$ duim dwars $=8 \%$ en 1 duim af $=0 \%$. Ses duime op gee dus 10()$\%$. James ${ }^{21.34}$ rapporteer ook seilplankprestasie as uiters goed, goed, gemiddeld, swak en uiters swak. Vir hierdie studie is dit soos volg omgewerk: uiters goed lê tussen $90 \%-100 \%$, goed tussen $80 \%-89 \%$, gemiddeld tussen $50-59 \%$, swak tussen $40 \%-49 \%$ en uiters swak tussen $0 \%-39 \%$. Waardes wat tussen laasgenoemde grense val, is egter ook aan seilplanke toegeken. In James ${ }^{24-35}$ se toetsprosedure word die seilplanke soms langs mekaar gery, met dieselfde takelasie en seilrigting, om die wenner te bepaal. Takelasies word geruil en dan word weer gery voordat'n finale wenner aangewys word. Soms word dieselfde vin vir al die seilplanke gebruik. In dic 1989-toetse van James $^{34}$ rapporteer elke toetsafnemer dadelik na sy eerste toets. Hierna verdeel die toetsers in 3 groepe van 2 , elk met 'n seilplank. Na elke rit ruil hulle seilplanke en vergelyk dan weer die prestasies van die seilplanke. Die prestasie-aspekte wat geëvalueer word, is windopspoed, windopdraaivermoë, windafspoed wat insluit $90^{\circ}$ met die wind en $120^{\circ}$ windaf (figuur 4), windaf draai (wye en kort draaie), versnelling, skeer, spring, ligtewindrybaarheid $(0-10$ knope $)$, mediumwindrybaarheid $(10-15$ knope) en sterkwindrybaarheid ( 15 knope en meer).

\section{Statistiek}

Omdat min metings van sommige veranderlikes voorgekom het, is al die moontlike onathanklike en afhanklike veranderlikes eers met mekaar gekorreleer met behulp van 'n BMDP6D-program ("Biomedical Computer Program") uit die BMDP- statistiese programpakket. ${ }^{23}$ Onafhanklike veranderlikes, massa, volume en breedte, wat onderling hoog korreleer, is hiervolgens uitgeskakel. Gevolglik verteenwoordig "lengte" homself en bogenoemde onathanklike veranderlikes.

Vervolgens is meervoudige liniêre regressie-ontledings ${ }^{38}$ op al die onafhanklike veranderlikes gedoen met behulp van die BMDP9R-program, soos weergegee in tabel 2. Hierdie veranderlikes is die deelversameling in tabel 2 wat (a) volledig gemeet is by die meeste afhanklike veranderlikes en (b) wel varieer by die gevalle (seilplanke) wat beskou is. Die derde laaste ry van tabel 2 gee die bepaaldheidskoëffisiënt $\left(R^{2}\right)$ van sodanige passings.

Omdat alle onathanklike veranderlikes nie ewe belangrik is by die voorspelling van die prestasie van seilplanke volgens elke afhanklike veranderlike nie, is stapsgewyse meervoudige regressie-ontledings met behulp van die BMDP2R-program ${ }^{23}$ gedoen. Hieruit is telkens stapsgewys slegs 'n deelversameling van onafhanklike veranderlikes geselekteer. Die $\mathrm{R}^{2}$-waardes van sodanige regressies word in die vierde laaste ry van tabel 3 gegee. As verdere metode om te besluit watter onafhanklike veranderlikes die beste deelversameling is, is die BMDP9R-program weer uitgevoer ten einde die "beste" deelversameling, met behulp van die sogenaamde alle-moontlike-deelversamelingsmetode, te bepaal. Hierdie resultate het in 'n groot mate met die van die stapsgewyse regressie ooreengestem. Die rigting waarin 'n afhanklike veranderlike deur 'n bepaalde onafhanklike 
veranderlike beïnvloed word, word as 'n plus- of minusteken in tabel 3 weergegee. Daarmee saam word ook die bydrae van elke gekose onafhanklike veranderlike tot $R^{2}$ gerapporteer. Dit is die hoeveelheid wat $R^{2}$ daal as die betrokke veranderlike uit die regressiepassing weggelaat sou word. Die bydraes tot $\mathrm{R}^{2}$ relatief tot mekaar gee' $n$ aanduiding van die mate waarin 'n betrokke onafhanklike veranderlike die onderhawige afhanklike veranderlike verklaar.

\section{RESULTATE}

Tabel 2 gee die bydraes tot $R^{2}$ soos reeds in die vorige paragraaf bespreek. Die resultate van sommige enkelvoudige korrelasies (veranderlikes wat nie met die meervoudige regressie-analises geanaliseer is nie), verskyn in tabel 3 . Weens die feit dat die hoeveelheid gevalle wat gekorreleer het, min was, is slegs die met 'n korrelasie (r) van 0,500 en hoër, en gebaseer op 10 of meer gevalle, in tabel 3 gerapporteer. Omdat die volume, breedte en massa van groot planke moontlik die ander veranderlikes as gevolg van interafhanklikheid tussen veranderlikes kon beïnvloed, is die data in groot en klein seilplanke verdeel. 'n Aparte meervoudige liniêre regressie-ontleding is vir klein en groot seilplanke gedoen; slegs die resultate van klein seilplanke is in tabel 4 gegee, omdat 'n soortgelyke ontleding van groot planke geen noemenswaardige resultate opgelewer het nie.

\section{BESPREKING}

Tabel 2 en 4 verteenwoordig slegs die veranderlikes wat geanaliseer is volgens die alle-moontlike-deelversamelingsmetode.Die volledige meervoudige regressies verteenwoordig die $\mathrm{R}^{2}$ van 25 (tabel 2) en 21 (tabel 4) veranderlikes. Die veranderlike "lengte" word in tabel 2 en 4 altyd in konteks met volume, massa en breedte gebruik. 'n $\mathrm{R}^{2}$ van 0,20 vir by voorbeeld "windop" beteken dat $20 \%$ van die prestasie "windop" se variansie of inligting deur die onafhanklike veranderlikes verklaar word. Die res van die variansie van "windop" is toe te skryf aan ander veranderlikes wat nie geanaliseer of gemeet is nie. "Subtiliteit" kon dieselfde

TABEL 2

Die bydraes van die onafhanklike veranderlikes tot $\mathbf{R}^{2}$

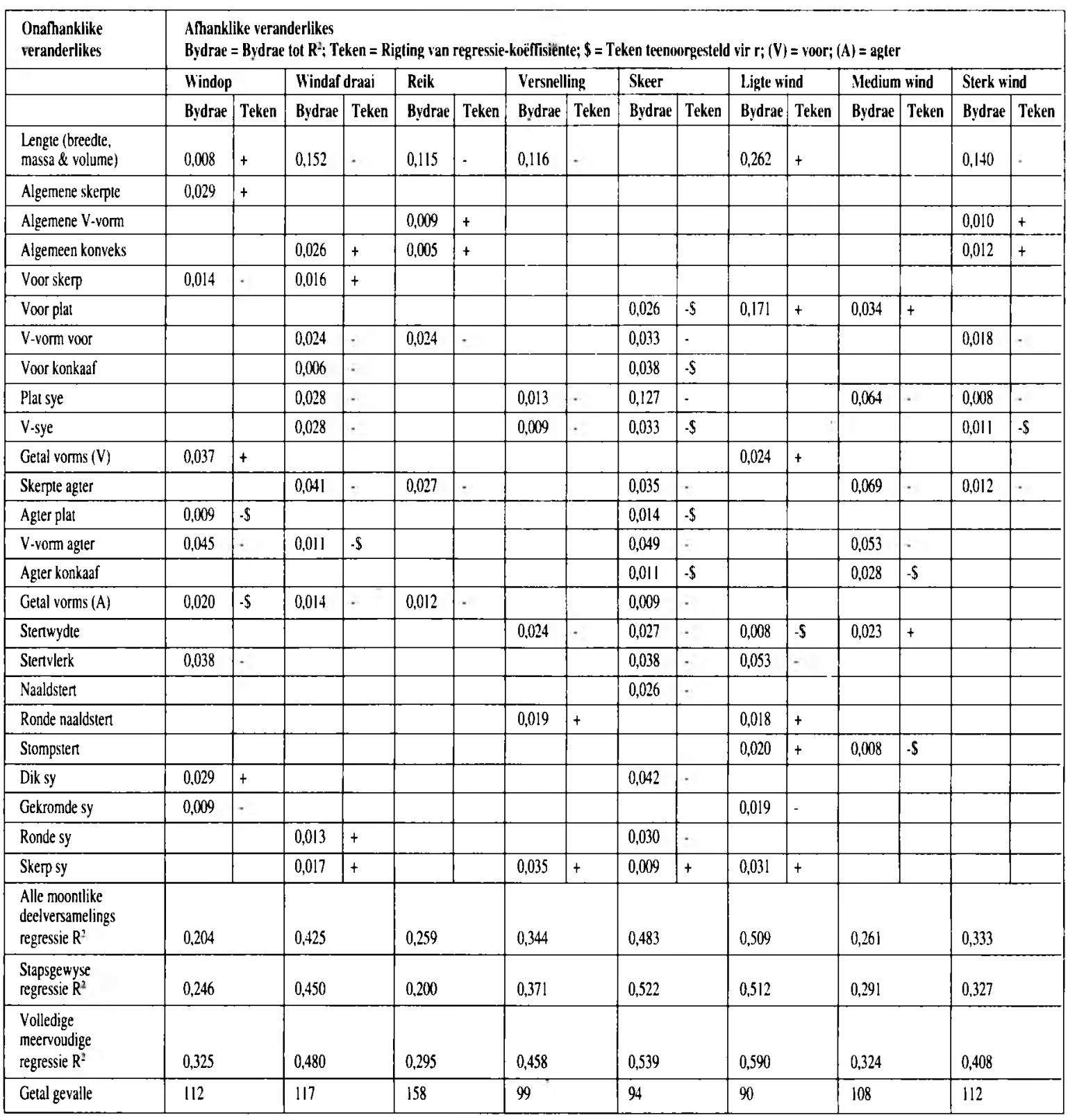


kwantitatiewe bydrae gelewer het as "skerpte", maar net teenoorgesteld in teken. "Subtiel" en "skerp" het by die enkelvoudige korrelasie-analise dieselfde korrelasie gehad. behalwe dat die teken teenoorgesteld is. Daarom is "subtiel" uit die analises as veranderlike weggelaat. Bogenoemde toepassing geld ook vir "algemene skerpte", "skerpte" in die voorste deel en "skerpte" in die agterste deel van die seilplank. Die meeste van die regressiekoëffisiënte is negatief, wat beteken dat die prestasie van seilplanke kan verbeter indien daar minder van hierdie vorms (kyk tabel 2 en 4) toegepas word, of indien die vorms minder prominent ingebou of heeltemal uit die ontwerpe van seilplanke weggelaat word. Tabel 4 is daargestel vir ontwerpers wat klein planke wil beplan.

In tabel 3 is slegs gevalle met $N>10$ gerapporteer. Die onafhanklike veranderlikes (neusboog, neuswydte, soutwaterdryfbaarheid, spring, stertwydte en varswaterdryfbaarheid), wat nie in die meervoudige regressies gerapporteer kon word nie omdat die rekenaar onvolledige gevalle uitgegooi het, is in tabel 3 gerapporteer. Hierdie veranderlikes is op ' $n$ intervalskaal gemeet.

Die volgende afleidings is uit tabel 2 gemaak. Die bespreking wat aan die hand van punt 1 gedoen word, dien as 'n voorbeeld vir 'n ontwerper om 'n seilplank volgens die resultate te ontwerp.

1. Die onafhanklike veranderlikes verklaar die prestasies
TABEL 3

\section{Enkelvoudige korrelasies tussen veranderlikes}

\begin{tabular}{|l|l|l|l|}
\hline $\begin{array}{l}\text { Onafhanklike } \\
\text { veranderlike }\end{array}$ & $\begin{array}{l}\text { Afhanklike } \\
\text { veranderlike }\end{array}$ & $\mathbf{r}$ & $\begin{array}{l}\text { Getal } \\
\text { gevalle }\end{array}$ \\
\hline Neusboog & Reik & $-0,687$ & 17 \\
\hline Stertwydte & Reik & $-0,626$ & 15 \\
\hline Neuswydte & Reik & $-0,648$ & 13 \\
\hline Neusboog & Skeer & $-0,516$ & 17 \\
\hline Stertwydte & Sterk wind & 0,820 & 15 \\
\hline Neuswydte & Sterk wind & 0,672 & 13 \\
\hline Stertwydte & Medium wind & 0,737 & 15 \\
\hline Neuswydte & Medium wind & 0,764 & 13 \\
\hline Stertboog & Ligte wind & 0,567 & 10 \\
\hline Varswaterdryfbaarheid & Ligte wind & 0,698 & 34 \\
\hline Soutwaterdryfbaarheid & Ligte wind & 0,698 & 34 \\
\hline Stertwydte & Ligte wind & 0,803 & 15 \\
\hline Neuswydte & Ligte wind & 0,592 & 13 \\
\hline Lengte & Spring & $-0,608$ & 43 \\
\hline Volume & Spring & $-0,607$ & 27 \\
\hline Massa & Spring & $-0,713$ & 30 \\
\hline Stertwydte & Spring & 0,591 & 11 \\
\hline Algemene V-vorm & Spring & $-0,515$ & 36 \\
\hline
\end{tabular}

TABEL 4

Bydraes tot $R^{2}$ van die onafhanklike veranderlikes vir klein planke (3,05 m en kleiner)

\begin{tabular}{|c|c|c|c|c|c|c|c|c|c|c|c|c|c|c|c|c|}
\hline \multirow[t]{3}{*}{$\begin{array}{l}\text { OnathankJike } \\
\text { veranderlikes }\end{array}$} & \multicolumn{16}{|c|}{$\begin{array}{l}\text { Athanklike veranderlikes van klein planke } \\
\text { Bydrae = Bydrae tot } \mathrm{K}^{\prime} ; \mathrm{Te}=\text { Rigting van regressie-koë́risiënte; }{ }^{*}=\mathrm{R}^{\prime} \text { gekorrigeer vir min gevalle; }(\mathrm{V})=\text { voor; }(\mathrm{A})=\text { agter }\end{array}$} \\
\hline & \multicolumn{2}{|c|}{ Windop } & \multicolumn{2}{|c|}{ Windaf draai } & \multicolumn{2}{|c|}{ Reik } & \multicolumn{2}{|c|}{ Versnelling } & \multicolumn{2}{|c|}{ Skeer } & \multicolumn{2}{|c|}{ Ligte wind } & \multicolumn{2}{|c|}{ Medium wind } & \multicolumn{2}{|c|}{ Sterk wind } \\
\hline & Bỹdrae & $\mathrm{Te}$ & Bydrae & $\mathrm{Te}$ & Bydrae & $\mathrm{Te}$ & Bydrae & $\mathrm{Te}$ & Bydrae & $\mathrm{Te}$ & Bydrae & $\mathrm{Te}$ & Bydrae & $\mathrm{Te}$ & Bydrae & $\mathrm{Te}$ \\
\hline $\begin{array}{l}\text { Lengte (breedte, } \\
\text { massa \& volume) }\end{array}$ & 0,003 & - & 0,015 & . & 0,025 & $\cdot$ & 0,022 & . & 0,015 & $\therefore$ & 0,058 & . & 0,006 & + & 0,033 & . \\
\hline Algemene skerple & 0,042 & + & 0,007 & + & 0,002 & + & 0,003 & + & 0,001 & - & 0,103 & + & 0,004 & - & 0,003 & + \\
\hline Algemeen plat & 0,010 & + & 0,001 & - & 0,023 & + & 0,001 & + & 0,030 & + & 0,026 & + & 0,019 & + & 0,003 & + \\
\hline Algemene V-vorm & 0,006 & - & 0,072 & . & 0,010 & + & 0,003 & + & 0,003 & + & 0,107 & - & 0,013 & + & 0,001 & + \\
\hline Voor skerp & 0,063 & . & 0,005 & - & 0,001 & + & 0,008 & . & 0,002 & - & 0,169 & - & 0,012 & + & 0,000 & + \\
\hline Voor plat & 0,050 & . & 0,001 & + & 0,025 & $\cdot$ & 0,042 & : & 0,077 & - & 0,010 & + & 0,007 & + & 0,001 & - \\
\hline Voor konkaaf & 0,031 & - & 0,027 & - & 0,065 & - & 0,035 & - & 0,080 & - & 0,036 & + & $0, \overline{013}$ & + & 0,001 & . \\
\hline Plat sye & 0,000 & $\therefore$ & 0,038 & - & 0,008 & - & 0,012 & - & 0,115 & - & 0,011 & + & 0,025 & + & 0,008 & + \\
\hline Getal vorms (V) & 0,047 & + & 0,074 & + & 0,027 & + & 0,009 & + & 0,052 & + & 0,043 & + & 0,021 & + & 0,010 & + \\
\hline Skerpte agter & 0,016 & + & 0,014 & . & 0,054 & - & 0,005 &. & 0,032 & - & 0,057 & + & 0,064 & - & 0,006 & . \\
\hline Agter plat & 0,025 & 5 & 0,000 & $\cdot$ & 0,022 & - & 0,023 & $\because$ & 0,046 & - & 0,017 & . & 0,049 & . & 0,059 & - \\
\hline V-vorm agter & 0,001 & - & 0,000 & + & 0,033 & - & 0,054 & . & 0,150 & - & 0,039 & - & 0,123 & - & 0,038 & - \\
\hline Agter konkaaf & 0,000 & - & 0,000 & $\cdot$ & 0,022 & - & 0,030 & . & 0,071 & - & 0,000 & - & 0,064 & $\cdot$ & 0,014 & - \\
\hline Getal vorms $(A)$ & 0,067 & . & 0,015 & - & 0,065 & - & 0,016 & - & 0,046 & . & 0,047 & + & 0,040 & - & 0.048 & - \\
\hline Stertwydle & 0,033 & - & 0,002 & {$[-$} & 0,000 & - & 0,010 & . & 0,003 & - & 0,002 & + & 0,084 & + & 0,045 & + \\
\hline Stertvlerk & 0,005 & - & 0,006 & + & 0,005 & + & 0,030 & + & 0,007 & - & 0,014 & . & 0,005 & + & 0,001 & - \\
\hline Naaldster & 0,007 & - & 0,015 & + & 0,000 & - & 0,012 & - & 0,053 & - & 0,001 & + & 0,029 & - & 0,028 & - \\
\hline Ronde naaldstert & 0,000 & + & 0,018 & + & 0,001 & - & 0,006 & . & 0,001 & - & 0,021 & + & 0,002 & + & 0,003 & - \\
\hline Stompster & 0,007 & - & 0,028 & + & 0,001 & . & 0,004 & . & 0,009 & - & 0,014 & + & 0,012 & + & 0,004 & - \\
\hline Ronde sy & 0,073 & - & 0,019 & + & 0,002 & - & 0,003 & . & 0,000 & + & 0,004 & + & 0,005 & + & 0,000 & 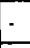 \\
\hline Skerp sy & 0,008 & + & 0,029 & + & 0,005 & + & 0,008 & + & 0,007 & + & 0,026 & + & 0,000 & + & 0,011 & + \\
\hline $\begin{array}{l}\text { Volledige } \\
\text { meervoudige } \\
\text { regressie } \mathrm{R}^{2}\end{array}$ & 0,711 & & 0,430 & & 0,392 & & 0,537 & & 0,797 & & 0,951 & & 0,591 & & 0,373 & \\
\hline Aangepaste $R^{*}$ & 0,477 & & $-0,030$ & & $-0,120$ & & 0,050 & & 0.546 & & 0,806 & & 0,260 & & $.0,134$ & \\
\hline Getal gevalle & 48 & & 48 & & 47 & & 42 & & 39 & & 29 & & 47 & & 47 & \\
\hline
\end{tabular}


van "windaf draai" $\left(R^{2}=0,4\right)$, skeer $\left(R^{2}=0,5\right)$ en ligte wind $\left(R^{2}=0,5\right)$ redelik goed. ' $n$ Seilplank kan gevolglik ontwerp word wat sal presteer op die gebied van "windaf draai", "skeer" en "ligte wind", mits die bydrae van 'n vorm nie teenstrydig is met die onderskeie prestasies nie. As 'n onafhanklike veranderlike min bydra, kan dit geïgnoreer word, of die bydrae positief of negatief is. As die bydrae groot is, byvoorbeeld "lengte" tot "windaf draai", moet dit in ag geneem word. Omdat lengte intervaldata is en ' $n$ regressiekoëffisiënt van $-0,152$ het, beteken dit dat, as die seilplank $1 \mathrm{~m}$ korter is, die prestasie van "windaf draai" $15,2 \%$ sal styg. As die onafhanklike veranderlike egter 'n negatiewe korrelasiekoëffisiënt het en digotome data (dit wil sê afwesig of teenwoordig) is, kan die vorm weggelaat word.'n Ontwerper kan hierdie beginsels oor die hele spektrum van prestasie toepas, en kan op dieselfde wyse ook oor die dwarste van tabel 2 besluit hoe hy ' $n$ vorm wil toepas. So lewer plat sye byvoorbeeld:

geen bydrae tot "windop", "reik" en "ligte wind" nie;

'n klein bydrae tot "versnelling" en "sterk wind"; en

groot negatiewe bydraes tot "windaf draai", "skeer" en "medium wind".

"Plat sye" kan gevolglik heeltemal weggelaat word oor die hele spektrum van prestasie. 'n Ontwerper sal egter nie altyd 'n vorm heeltemal kan weglaat sonder om sommige aspekte van prestasie te benadeel nie. Hy sal moet besluit vir watter windtoestande en aspekte van prestasie hy 'n seilplank wil ontwerp.

2. Dit is duidelik dat daar nie een seilplankontwerp wat alle onderskeie prestasies bevredig, voorgeskryf kan word nie, en dat ontwerpers eerder die onderskeie vorms self moet saamstel vir spesifieke doelwitte.

3. Dit is duidelik dat $90 \%$ van die vorms in tabel 2 'n negatiewe korrelasiekoëffisiënt gee.

Dieselfde afleidings wat uit tabel 2 gemaak is, geld ook vir tabel 4 , behalwe:

dat verskillende onafhanklike veranderlikes deur die rekenaar gekies is;

dat volgens die aangepaste $\mathrm{R}^{2}$ "windop" nou goed en "windaf draai" nie goed deur die onafhanklike veranderlikes verklaar word;

dat "lengte" se bydrae oor die hele spektrum van prestasie baie kleiner is en

dat negatiewe ( $58 \%$ ) en positiewe $(42 \%$ ) bydraes van die onafhanklike veranderlikes ongeveer eweveel is.

Ontwerpers kan ook uit tabel 3 keuses doen ten opsigte van vorms omdat:

goeie r-waardes verkry is en alle korrelasies behalwe "stertwydte" met "sterk wind" en "stertboog" met "ligte wind" sinvol en teoreties verklaarbaar is.

\section{GEVOLGTREKKINGS EN AANBEVELINGS}

Die volgende algemene gevolgtrekkings en aanbevelings is moontlik:

1. Dit gaan moeilik wees om een seilplank te bou wat in alle windtoestande en oor die hele spektrum van prestasie presteer.

2. Indien veranderlikes soos planvorm en stertboog, wat nie in hierdie analise ingesluit is nie, bygevoeg kon word, kan dit veroorsaak dat 'n ontwerp saamgestel kan word wat 'n breër spektrum van prestasie bedien.

3. Ontwerpers kan die resultate sinvol gebruik vir die ontwerp van seilplanke.

4. Beter evaluasie van seilplankprestasie deur die vervaardigers kan lei tot beter analises.

\section{LITERATUURVERWYSINGS}

I. Dunstan-Smith, R. (1985a). Board test, Boardsailor, 4(3), 25, 27.

2. Dunstan-Smith, R. (1985b). Board test, Boardsailor, 4(8), 29, 31, 34 36.

3. Dunstan-Smith, R. (1986a). Board test, Boardsailor, 5(4), 14, 17, 18 \& 32.

4. Dunstan-Smith, R. (1986b). Board test, Boardsailor, 5(5), 28, 29, 30 \& 31.

5. Dunstan-Smith, R. (1986c). Board test, Boardsailor, 5(6), 26, 28, 32. $33,44$.

6. Dunstan-Smith, R. (1986d). Board test, Boardsailor, 5(7), 29, 32.

7. Dunstan-Smith, R. (1986e). Board test, Boardsailor, 5(8), 11, 25, 35.

8. Dunstan-Smith, R. (1986f). Board test, Boardsailor, 5(9), 16, $28,37$.

9. Dunstan-Smith, R. (1987a). Board test, Boardsailor, 6(3), 13, 14, 20, $21,24-26$.

10. Dunstan-Smith, R. (1987b). Board test, Boardsailor, 6(4), 12, 20.

11. Dunstan-Smith, R. (1987c). Board test, Bourdsailor, 6(7), 18.

12. Dunstan-Smith, R. (1987d). Board'87 test, Boardsailor, 6(8), 29, 30, 32 , 46.

13. Dunstan-Smith, R. (1987e). Board'87 test, Boardsailor, 6(9), 8, 25, 28, 29.

14. Dunstan-Smith, R. (1987f). Board'87 test, Boardsailor, 6(10), 28, 34.

15. Dunstan-Smith, R. (1987g). Board'87 test, Boardsailor, 6(11), 16, 20. $25,34,46$.

16. Dunstan-Smith, R. (1988a). Board'88 test, Boardsailor, 7(3), 22, 24.

17. Dunstan-Smith, R. (1988b). Board'88 test, Boardsailor, 7(10), 28.

18. Dunstan-Smith, R. (1988c). Board'88 test, Boardsailor, 7(11), 36-39.

19. Erbe, A. (1989a). Five slalom hot shots for ' 89 , Windsurf Magazine, March, no. 85, 14-18.

20. Erbe, A. (1989b). Three steps to heaven, Windsurf Magazine, April, no. $86,14-18$

21. Gadd, A. (1986). A new development in boards, Boardsailor, 5(9), 23.

22. Hart, P. (1989). 40,48 Knots, Windsurf Magazine, March, no. 85, 50 54.

23. Hill, M. (1987). BMDP User's digest. A condensed guide to the BMDP computer programs, 4th edition. Los Angeles, BMDP Statistical Software, Inc. p. I - 157.

24. James, T. (1987a). Windrider board'87 tests, Windrider, 6(4), $64-80$.

25. James, T. (1987b). Windrider board' 87 tests, Windrider, 6(5), 60-75.

26. James, T. (1987c). Windrider board' 87 tests. Windrider, 6(6), $54-70$.

27. James, T. (1988a). Windrider board'87 tests, High wind slalom boards, Windrider, 7(1), 66 - 79 .

28. James, T. (1988b). Windrider board' 88 tests, Windrider, 7(2), $77-95$.

29. James, T. (1988c). Sailing the pro's rigs, Windrider, 7(2), 46-52.

30. James, T. (1988d). Windrider board'88 tests, Windrider, 7(3), $54-65$.

31. James, T. (1988e). The bottom line, Windrider, 7(5), $42-47$.

32. James, T. (1988f). Windrider board' 88 tests, Windrider, 7(5), $60-79$.

33. James, T. (1988g). Windrider board'88 tests, Windrider, 7(6), $64-71$.

34. James, T. (1989a). Windrider board'88 tests, Windrider, 8(1), $64-84$.

35. James, T. (1989b). Gorge built, Windrider, 8(3), $105-114$.

36. Jessop, E. (1985). Board review, Sweet F2. On Board, 6(5), 48 - 50.

37. Kasprowicz, M. (1988). Coarse bred, Windsurfand Boardsailing, August, no. $81,58-59$. 
38. Kerlingel, F.N. \& Pedhazur, E.J. ( 1973). Multiple regression in behavioral research. Ilol1, Reinhart \& Winston, New York pp. 282, 283, 534.

39. Larned. C. (1989). Equipment clinic part two, Windsurf, 19(2), 30-31.

40. Le Mehaute, P. (1989). Technical lests, Windrider. 7(1), 68.

41. Le Mehaute, P. (1989b). Windrider board'89 tests, Windrider, 8( ) , 64 -84 .

42. Murdoch, P. (1987). Sufface flow, Windsurf, 17(12), 46-47.

43. Norman, T. (1987). The double inverted "V", Boardsailor, 6(11), 20.

44. Norman, T. (1989), Surface flow, Freewind, August/Sept., no. 12. Ish. no. $10109528,27$.

45. Norman, T., Slate, P. \& Masterton, T. (1987). The pro's quivers, Beardsailor, $6(10), 18-19$.
46. Rogers, K. (1987a). Eq., Windsurf, 17(11), 68-70.

47. Rogers. K. (1987b). Eq., Windsurf, 17(12), 69-71.

48. Rogers. K. (1988). Eq., Windsurf. 18(7), $74-79$.

49. Rogers, K. (1989a). H.q.-tests, Windsurf, 19(2), $62-64$.

50. Rogers, K. (1989b). Test: Coarse racers, Windsurf, 19(5), $75-79$.

51. Rogers, K. (1989c). Test: Speed boards, Windsurf, 19(6), $73-75$.

52. Rogers, K. (1989d). Test: Mistral screamer vs. F2 sunset race, Windsurf, $19(6) .80-81$

53. Stonchause, S., Palmer, R. \& Eberlin, D. (1985). Bless them all. On Board, $6(5), 76-77$

54. Visser, J.H. (1987). Airmail, Boardsailor, 6(2), 7. 